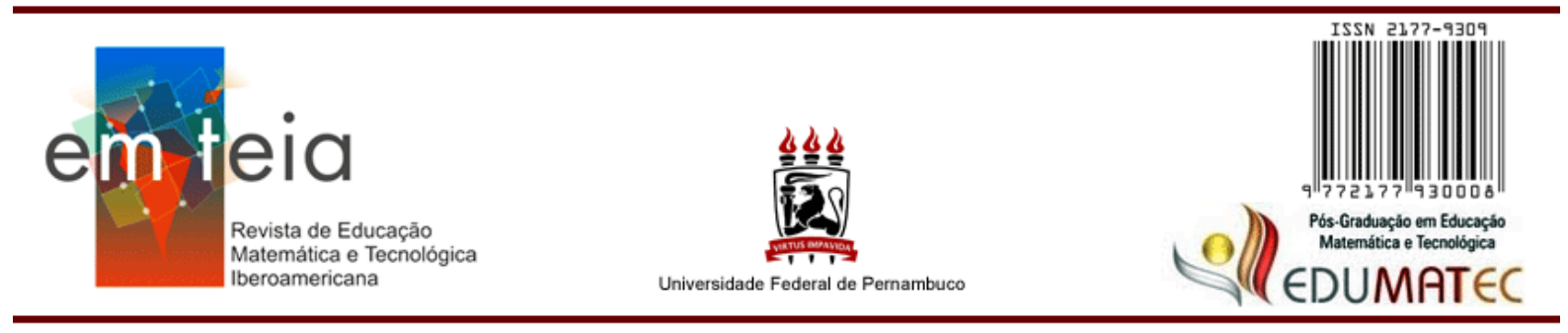

\title{
VISÕES SOBRE A CONVERGÊNCIA NA EDUCAÇÃO EM DIFERENTES PERSPECTIVAS: NOVAS PERCEPÇÕES E TENDÊNCIAS
}

\author{
Daniela Melaré Vieira Barros \\ Departamento de Educação e Ensino a Distância \\ Universidade Aberta - Portugal \\ Membro do Centro de Investigação CEIS XX \\ Universidade de Coimbra \\ Colaboradora do LE@D - Universidade Aberta \\ daniela.barros@uab.pt
}

Fernanda Araújo Coutinho Campos

APRESENTAÇÃO

fernandaaccampos@gmail.com

A temática da convergência é contemporânea e exige observação e reflexão transdisciplinar, uma vez que diz respeito à cultura dos tempos hodiernos e às relações sociais, modificadas com e por meio das Tecnologias Digitais da Informação e da Comunicação (TDIC). Envolve as áreas das tecnologias, da comunicação, das artes, da sociologia e, no caso do nosso trabalho, da educação.

Vivemos tempos de imersão digital, de convívio diário e constante das TDIC. Entretanto, ao pensar a educação, verifica-se uma divisão das experiências entre as que são face-a-face e as virtuais. Nessa divisão, é estabelecida uma dicotomia e hierarquia, em que normalmente a educação presencial é considerada mais relevante.

Observando a cultura e as relações sociais produzidas com o virtual e as tecnologias no contexto educativo, elaboramos como hipótese a convergência da educação presencial e a distância como uma possibilidade para o ensino superior. No entanto, a nossa constatação partia do princípio de que a convergência se daria pela integração da educação presencial e da educação a distância. Tínhamos como mote a compreensão da cultura da convergência nos 
seus fundamentos e reflexões de base, juntamente com as questões da legislação brasileira, como a Portaria 4.059/2004.

A Portaria $4.059 / 2004^{1}$ permitia que $20 \%$ da carga horária dos cursos presenciais fossem ofertadas utilizando-se da Tecnologia da Informação e da Comunicação para mediar atividades pedagógicas:

[...] como quaisquer atividades didático-pedagógicas, módulos ou unidades de ensino-aprendizagem centrados na autoaprendizagem e com a mediação de recursos didáticos organizados em diferentes suportes de informação que utilizam tecnologias de comunicação remota (BRASIL, 2004).

A cultura da convergência, definida por Jenkins (2009), pode ser compreendida sinteticamente como as relações estabelecidas entre os espectadores e os média; além das mudanças ocorridas com a produção de conteúdo, seja ele cinematográfico, televisivo, literário ou outro, em que o processo transmidiático, o uso e o estabelecimento de redes criam novos cenários e produtos. Este estudo, a partir dos seus fundamentos, incitou-nos a pensar sobre os cenários estabelecidos com o uso das tecnologias na educação e, assim, as possibilidades de convergência neste contexto.

Tendo estas duas referências - a cultura da convergência e a Portaria 4.059/2004 - foi realizada a investigação doutoral, denominada "Convergência na educação: Políticas, tecnologias digitais e relações pedagógicas" (CAMPOS, 2017), cujo objetivo geral era compreender a convergência na educação como uma possibilidade para o ensino superior. Entre os desdobramentos da pesquisa, realizamos entrevistas com cinco docentes da Universidade Aberta de Portugal buscando conhecer suas concepções sobre a temática da convergência. A partir das diferentes perspectivas, sintetizamos aqui as novas percepções e as tendências verificadas.

Informamos que a investigação realizada com os docentes da Universidade Aberta (UAb - Portugal) se deveu à oportunidade do estágio doutoral, durante doze meses (setembro 2014 - agosto 2015), nesta instituição².

\footnotetext{
${ }^{1}$ Esta Portaria permitiu às instituições de ensino superior a introdução de atividades didáticas, módulos ou unidades de ensino na modalidade semipresencial. Informamos os nossos leitores que esta Portaria foi revogada em 2016, por meio da Portaria 1134/2016.

2 Programa de Doutorado Sanduíche (PDSE), realizado com financiamento da CAPES entre agosto de 2014 e setembro de 2015 (Processo PDSE 99999.004239/2014-08).
} 
É importante ressaltar que a noção de convergência na educação foi construída a partir das concepções transdisciplinares das áreas da comunicação, da tecnologia e das artes. A ideia inicial restringia-se à convergência da educação presencial e de educação a distância (descontruída rapidamente a partir dos nossos estudos), porque acreditávamos que era necessário romper a dicotomia entre elas e pensar única e exclusivamente no objetivo educacional.

A convergência, seja ela mediática, tecnológica ou educativa, contextualiza-se como parte da sociedade em rede, conforme elucidada por Castells (2013, p. 30) como “(...) uma estrutura social em torno (mas não determinada por) das redes digitais de comunicação". Desde o início do século XXI, passamos a vivenciar uma nova experiência social onde se destaca a revolução tecnológica, a remodelação da sociedade e a nova forma de relação entre a economia, o estado e a sociedade, em que

(...) a estrutura social é composta de redes ativadas por TIC baseada na microeletrônica. Entendo por estrutura social os acordos organizativos humanos na relação com a produção, com o consumo, a reprodução, a experiência e o poder expressos por uma comunicação significativa codificada pela cultura (CASTELLS, 2013, p. 58).

As conexões, mediadas pelas TIC, estabelecidas em rede, permitem a mobilização de uma cultura própria fruto das relações em rede, em que Lemos (2010) - apoiado nas ideias de Levy (1997) de cibercultura -, acredita que a conectividade entre pessoas e computadores

[...] forma-se precisamente, da convergência entre o social e o tecnológico, sendo através da inclusão da sociabilidade na prática diária da tecnologia que ela adquire seus contornos mais nítidos. Não se trata, obviamente, de nenhum determinismo social ou tecnológico, e sim de um processo simbiótico, onde nenhuma das partes determina impiedosamente a outra (2010, p. 88-89).

Esta convergência social promove, de acordo com Jenkins (2009), novas relações entre espectadores e a produção midiática caracterizando a cultura da convergência, que envolve a convergência dos meios de comunicação, a cultura participativa e a inteligência coletiva, ou seja, meios de comunicação, participação e conexão. Na compreensão deste autor, convergência “(...) representa uma transformação cultural, à medida que consumidores são incentivados a procurar novas informações e fazer conexões em conteúdos de mídias dispersos" (JENKINS, 2009, p. 2930). 
Salientamos que a convergência envolve questões contemporâneas e não se define por determinismo tecnológico, nem tão pouco restrito a ferramentas midiáticas; antes de mais, convergência é cultural e social, formada pelas relações entre sujeitos em rede, em que prevalecem a colaboração, a interação, a flexibilidade, a partilha, a inovação, a autonomia e a mobilidade. Assim, a convergência deve ser compreendida como parte dos atuais processos de transformação social, tecnológica, cultural e educativa.

Este trabalho justifica a sua importância por se tratar de uma temática atual e relevante para pensar a composição da convergência na educação. De tal modo, a contribuir para a reflexão e o enfrentamento sobre os paradigmas tradicionais da educação frente às novas Tecnologias Digitais da Informação e da Comunicação (TDIC), assim como as potencialidades da convergência para o ensino superior.

Diante deste preâmbulo, salientamos que o objetivo deste artigo consiste em analisar, a partir de entrevistas aplicadas, as novas percepções sobre a convergência na educação, suas possibilidades e tendências para o ensino superior. O leitor irá encontrar a seguir os elementos da fundamentação teórica, as considerações metodológicas, a análise das entrevistas, os resultados e as considerações finais.

\section{OS SENTIDOS DA CONVERGÊNCIA}

A convergência compreende-se nas suas múltiplas dimensões, afinal é multidisciplinar e polissêmica, e, por isto mesmo, verifica-se em campos do conhecimento distintos. Partindo do princípio, sabemos que convergência significa "ato de convergir; junção num ponto; tendência para o mesmo resultado" conforme o Dicionário da Língua Portuguesa (2011, p. 420).

Nesta direção, buscamos entender que a convergência na educação se compõe pela junção de múltiplas dimensões em que se destacam as tecnologias, nomeadamente as Tecnologias da Informação e da Comunicação (TDIC); dos materiais (textos, imagens, vídeos, jogos, fóruns etc.), dos espaços (físicos e virtuais); das relações pedagógicas (interação, colaboração, conectividade, compartilhamento); das modalidades (presencial e a distância); e das formas (formais e informais), com uma finalidade comum: a educação.

Esta constatação fez-se a partir das dimensões complementares eleitas em nossa investigação que englobam os campos da tecnologia, das artes e da comunicação, em que 
verificamos pontos transversais a essas áreas com a educação, no que se refere sobremaneira às Tecnologias Digitais da Informação e da Comunicação. Entretanto, salientamos que esta análise não se limita ao material ou ao hardware, mas, antes de mais, nas relações sociais estabelecidas entre os sujeitos em rede, em que se verificam a colaboração, a interação, a conectividade, a produção de conteúdos, o compartilhamento, como características imprescindíveis para a concretização da convergência.

$\mathrm{Na}$ dimensão das tecnologias, entende-se que a convergência se caracteriza pela integração das telecomunicações e da microeletrônica, constituindo uma nova forma de comunicação (CASTELLS, 2003). Acrescentamos que ela se compõe pela multiplicidade e pela diferença de níveis, em termos de infraestrutura, de serviços e de equipamentos, e, não menos importante, de que ela não se faz apenas pela tecnologia, mas pela interação social, e de novos modos de transmissão de dados, permitindo que "os serviços de comunicação tradicional - de voz, dados, som ou imagens - passasse a ser fornecido ao longo de muitas redes diferentes" ${ }^{3}$. E se tipifica pela indefinição das fronteiras entre a telecomunicação, os media e tecnologia da informação, conforme Freitas e Griffiths $(2008)^{4}$ e pela "mobilidade, que é o fator chave para qualquer estratégia de convergência" 5 (ENYEART; STAMAN; JR. VANDES, 2007, p. 48), se compondo, desta forma, como uma rede de múltiplos meios e tecnologias, coexistindo através dos mesmos canais tecnológicos ${ }^{6}$ (CERVANTES, 2009, p. 68). Outro aspeto da convergência tecnológica é o cultural, pois “convergência não é apenas sobre tecnologia. É sobre serviços e sobre novas formas de fazer negócios e interagir socialmente"7 (EUROPEAN COMISSION, 1997, p. 2). Ou ainda, segundo Castells (2013, p. 188), a

\footnotetext{
3 Tradução livre para: (...) that is to say that digital technology now allows both traditional and new communication services - whether voice, data, sound or pictures - to be provided over many different networks (EUROPEAN COMISSION, 1997, p. 2).

${ }^{4}$ Tradução livre para: (...) Resulting in the blurring of lins between media forms witch typifies media convergence (FREITAS; GRIFFITHS, 2008, p. 11).

${ }^{5}$ Tradução livre para: (...) Mobility is a key factor and must be considered in any convergence strategy (ENYEART; STAMAN, JR; VANDES, 2007, p. 48).

${ }^{6}$ Tradução livre para: (...) es entendida como un entorno en red, cuya transparencia permite que tecnología e contenido confluyan en una sola industria de múltiples medios y tecnologías. En otras palabras, es la coexistencia no excluyente de distintos formatos a través de los mismos canales tecnológicos (CERVANTES, 2009, p. 68).

${ }^{7}$ Tradução livre para: (...) Convergence is not just about technology. It is about services and about new aways of doing business and of interacting with society (EUROPEAN COMISSION, 1997, p. 2).
} 
"convergência é fundamentalmente cultural, e produz-se, em primeiro lugar nas mentes dos sujeitos comunicadores que integram vários modos e canais de comunicação nos seus costumes e na sua interação". De modo sintético, a convergência pode ser compreendida, portanto, como a integração das telecomunicações e da informática, que viabilizam novas formas culturais de comunicar e de transmitir dados, em que as barreiras entre os recursos se encontram cada vez mais indefinidos.

No campo comunicacional, Jenkins (2009) define as mudanças culturais no modo de relacionar com o conteúdo midiático - seja programas de televisão, filmes, livros, jogos, redes sociais - tendo em vista o fluxo de conteúdo, os múltiplos suportes, o comportamento das audiências e a cooperação de mercados midiáticos como "Cultura da convergência". A partir dos argumentos deste pesquisador, entendemos que assistir televisão deixa de ser uma ação isolada e solitária. Assiste-se aos programas televisivos e comenta-se simultaneamente em alguma rede social - Facebook ou Twitter, por exemplo - criando audiências comunitárias e não mais individuais, inclusive, tendo os próprios programas os seus perfis e hashtags específicos, como um canal aberto para falar com o espectador. Este, por sua vez, comenta, critica, pergunta, envia elogios e se sente "mais próximo" dos apresentadores. A produção cinematográfica é outro exemplo, pois, agora, não se realiza apenas um filme, muitos deles se expandem às narrativas transmidiáticas, e, a partir de um produto midiático (filme), estabelece-se uma rede de mídias, entre jogos, histórias em quadrinhos, curta metragens, blogs, fóruns entre outros.

Na cultura da convergência, a interatividade e a participação são imprescindíveis, pois entende-se não só apenas como os mídias se integram, mas a forma como as pessoas se relacionam com eles. A interatividade, conforme Silva (2010), é a grande mudança no contexto da cibercultura. Esta ganha centralidade, na medida em que a mensagem sofre modificações de quem a manipula, o emissor constrói uma rede labiríntica de informações e o receptor consegue manipular a mensagem, tornando-se coautor. A denominada cultura da convergência pode ser observada e vivenciada por aqueles com acesso à internet e que fazem uso dela, não como espectadores, mas como atores e produtores de conteúdo.

A convergência nas artes foi analisada a partir da obra de Santaella (2005) que questiona: por que as comunicações e as artes estão convergindo?. A autora compreende a convergência como um ato em que "[...] convergir não significa identificar-se. Significa isto 
sim, tomar rumos que, não obstante as diferenças, dirijam-se para a ocupação de territórios comuns, nos quais as diferenças se roçam sem perder seus contornos próprios" $(2005$, p. 7).

Essa aproximação das diferenças tornou-se evidente nas belas artes, a partir do século $X X$, quando a comunicação de massa (MCLUHAN, 2005) se desenvolveu. Destaca que o processo de convergência entre os meios de comunicação e as artes não excluiu os antigos processos artísticos, mas provocou novas formas de criação, de modo a possibilitar diferentes experiências estéticas e sensoriais. Assim, mesclam-se artes plásticas com nanotecnologia, biologia, ciência, tecnologia.... os contornos se estreitam e novos são traçados.

Criam-se novas relações entre artistas e espectadores, fazendo-nos refletir sobre o novo papel. Se antes era espectador, agora tornou-se também participador. Essa concepção ecoará no campo educativo. Diferente das aulas que eram preparadas de modo tradicional, ou seja, somente o professor era o responsável pelo conteúdo, na atualidade tem se requerido dos alunos uma maior participação, interação e construção do conhecimento.

Retornamos aos argumentos de Santaella (2005), para dizer que a convergência dos media possibilita ao usuário criar, distribuir e consumir informação, pois diz respeito à impossibilidade de separação entre as culturas eruditas, populares e massivas. A convergência dos medias faz parte da cultura digital (NEGROPONTE, 1995), que se caracteriza pela coexistência da cultura de massas e da cultura dos medias (SANTAELLA, 1996).

Desta forma, entendemos que os sentidos da convergência, por um lado, se constituem a partir das novas formas de lidar com a comunicação, com a informação e com a produção de conteúdo, sobremaneira, com as relações sociais estabelecidas em rede (DIAS, 2013; DIAS et al., 2016), estabelecendo comunidades online. Conforme Dias (2013, p. 1),

[...] as comunidades online, com sociabilidades e relações próprias ao espaço do virtual, são um meio e o suporte para a partilha da informação, o envolvimento na construção colaborativa das aprendizagens e a criação de novo conhecimento. Deste modo, a comunidade online é uma rede de afinidades, de interesses partilhados e um espaço para a contextualização e a realização das aprendizagens que expande as possibilidades dos modelos presenciais para o potencial da imersão nas representações distribuídas na rede.

E, por outro, em perceber que esse processo traz e trará reconfigurações nos modos de se pensar e de se fazer a educação, sem a necessidade de estar presente fisicamente nos espaços formativos ou ainda das novas formas de estar em salas de aula, pois, na 
convergência, os espaços educativos são infinitos e a presença se faz por participações e interações.

\section{METODOLOGIA}

Buscando analisar, a partir de entrevistas aplicadas, as novas percepções sobre a convergência na educação, suas possibilidades e tendências para o ensino superior, entrevistamos cinco docentes da Universidade Aberta, Lisboa, Portugal, uma universidade pública de ensino a distância e com um modelo pedagógico próprio, premiado e totalmente online e assíncrono.

No período do estágio doutoral, de setembro de 2014 a agosto de 2015, realizado na Uab, os objetivos eram aproximar-se aos grupos de pesquisas portugueses na área da educação a distância, fazer levantamento bibliográfico de investigações realizadas em Portugal sobre o tema da convergência e estudar as políticas educacionais portuguesas para o ensino superior. Dentre esses objetivos, as entrevistas foram acrescidas como sugestão das orientações em Portugal; essas ocorreram entre dezembro de 2014 e janeiro de 2015, com duração média de uma hora. As entrevistas foram realizadas após levantamento bibliográfico e em 5 fases: elaboração do roteiro, validação por especialistas, realização de entrevistas, análise de conteúdo e, por fim, elaboração da análise geral.

O instrumento utilizado foi uma entrevista semiestruturada e a análise de conteúdo para o tratamento dos dados. O guião da entrevista foi composto por 25 questões com base nas categorias: Educação para a convergência no ensino superior; Educação a Distância e as Políticas Educativas para o ensino superior; Relações educativas e Orientação Pedagógica; Organização Institucional.

A abordagem qualitativa se fez necessária pelo fato do objeto de investigação ser complexo em meio à realidade atual, uma das características requeridas para esse tipo de investigação.

A seleção e escolha dos cinco professores entrevistados ${ }^{8}$ teve como critérios: terem experiência na temática de estudo e por práticas propostas para a UAb; serem professores

\footnotetext{
8 Por um procedimento do comitê de ética, neste trabalho eles serão referenciados por suas iniciais. As entrevistas tiveram duração média de 1 hora e foram realizadas entre os meses de dezembro de 2014 e janeiro de 2015
} 
que estavam na instituição há pelo menos 10 anos e possuírem experiência tanto na educação presencial quanto na educação a distância.

O guião foi validado por três professores doutores na área dando sugestões sobre as questões propostas, contribuindo de forma qualitativa. As entrevistas foram transcritas na sua totalidade pela autora e retornadas aos entrevistados, que fizeram considerações na transcrição e validaram a mesma.

Utilizamos o método de análise de conteúdo proposto por Bardin (1977, p. 81) segundo o qual "(...) é certo que o gênero dos resultados obtidos pelas técnicas de análise de conteúdo não pode ser tomado como prova inelutável. Mas constitui-se, apesar de tudo, uma ilustração que permite corroborar, pelo menos parcialmente, os pressupostos em causa".

Após a transcrição das entrevistas, foi realizada a análise de conteúdo, que permitiu definir as seguintes categorias e subcategorias, respetivamente:

QUADRO 1: Categorias e subcategorias de análise das entrevistas

\begin{tabular}{|l|l|}
\hline \multicolumn{1}{|c|}{ Categorias } & \multicolumn{1}{c|}{ Subcategorias } \\
\hline Modalidades educativas & - Características das modalidades presencial e a distância \\
\hline Convergência educativa & - Complementariedade \\
& - Convergência presencial e a distância \\
\hline Políticas educativas & - Regulamentação \\
& - Pressupostos educativos para o século XXI \\
\hline Integração presencial e a distância & - Blended Learning \\
& - Modelos híbridos e turmas mistas \\
& - Síncrono e assíncrono \\
& - Polos e Centros Locais de Aprendizagem \\
& - Relações pedagógicas \\
& - Modelos pedagógicos \\
& - Tecnologias da informação e da comunicação \\
\hline
\end{tabular}

Devido à delimitação espacial, neste artigo apresentamos as seguintes categorias: Modalidades educativas e Convergência na educação. Estas categorias foram escolhidas por exporem de forma mais explícita a compreensão da convergência. As demais categorias contribuíram para compreender as políticas e outros assuntos gerais.

\section{O QUE DIZEM OS PROFESSORES SOBRE A CONVERGÊNCIA NA EDUCAÇÃO DO ENSINO SUPERIOR: NOVAS PERCEPÇÕES E TENDÊNCIAS}

A ideia inicial sobre a convergência na educação era de que ocorreria de uma forma quase linear da educação presencial e da educação a distância. Todavia, entendendo os 
sentidos da convergência, e também com o auxílio das entrevistas realizadas, pudemos verificar que a concretização da convergência se faz por outros caminhos, nem sequer lineares e tão pouco formais/institucionais.

Iniciamos a entrevista por uma questão que considerávamos pertinente para entender de que modo se daria a convergência: quais as distinções e semelhanças entre as modalidades presencial e a distância?

O fato dos sujeitos da pesquisa terem experiência nas duas modalidades e serem pesquisadores da área da educação deu origem a que as definições tenham sido explicitadas de modo similar e também próximas às designações que encontramos na teoria, em que a modalidade presencial é definida pela presencialidade física, face-a-face, em que os sujeitos estão no mesmo espaço e no mesmo tempo para realizar o processo de ensino aprendizagem, enquanto que na modalidade a distância os sujeitos estão geográfica e temporalmente dispersos. Há uma noção de virtualidade, pois a interação é mediada por um meio de comunicação (correspondência, rádio, televisão, ambientes virtuais de aprendizagem e outros).

A este respeito, percebemos que a diferença se baseia, sobretudo, em aspetos geográficos (físico e temporal) e comunicativos (meio de comunicação). No caso da modalidade presencial, a presencialidade física no mesmo espaço e o tempo síncrono são necessários para que sejam estabelecidas as relações pedagógicas. Por outro lado, na modalidade a distância o espaço e o tempo tornam-se flexíveis, pois os sujeitos encontram-se geográfica e temporalmente separados, de modo que as atividades assíncronas têm relevância, assim como os recursos elegidos para mediar a comunicação. Na atualidade, com o uso de plataformas virtuais, a educação a distância adquire um status diferente do que até então se experiencia, quando os recursos mediadores eram a correspondência, o rádio e a televisão, pois permite uma interação frequente entre os sujeitos em múltiplas direções (professor - estudantes; estudantes - estudantes; estudantes - materiais), tornando-se, assim, mais próxima dos modelos presenciais, conforme entende a professora L.A.:

[...] eu acho que antes tinha muito mais diferença entre o presencial e o a distância do que atualmente. Não sei se posso ir fazendo essa comparação. Porque no sistema mais tradicional de educação a distância a interação era apenas entre alunos e materiais, aluno e professor, mas você não tinha o papel do grupo. Enquanto que, a partir do momento em que, estas novas ferramentas tecnológicas passaram a sustentar a educação a distância; a educação a distância ganha uma espécie de sala 
de aula virtual, que até aí não existia. Portanto, o que quer dizer que as diferenças que existiam dantes entre o presencial e a distância eu acho que eram muito maiores, precisamente, porque não havia esse espaço comum, não havia essa interação entre pares (Professora LA).

A questão da presença também adquire nova configuração no modelo atual, que se baseia em interação mediada por computador e plataformas interativas, assim que, em concordância com a teoria de Garrison, Anderson e Archer (2000), definem-se a presença docente, social e cognitiva, resgatada pelo professor A.M.:

[...] O conceito da presença obviamente que tá presente, passa por essa redundância, nas duas modalidades, não é? Existe inclusive em modelos pedagógicos virtuais que implicam a presença em diferentes níveis, seja a nível da presença social, seja da presença docente, seja da presença cognitiva; portanto, há um modelo que é essencialmente do Garrison que se baseia um pouco no diálogo dessas diferentes presenças. Estamos a falar de uma presença que não se traduz na dimensão da presença física, portanto, obviamente, que quando estamos a falar em modalidades presencial - não sei se era o sentido - estamos a falar mais na tal modalidade conservadora, que implica uma presença física e que não haja uma distância entre aquele que são atores educativos normalmente - o professor e o estudante (Professor AM) .

Nesse sentido, percebemos que se antes a educação a distância e a educação presencial eram modalidades com diferenças significativas, essas diferenças têm vindo a dissolver-se em termos das possibilidades de interação ou da compreensão de presença.

Mesmo com a expansão verificada na EaD, e com a aproximação das atividades e das concepções, constatamos uma permanente dicotomia entre as modalidades presencial e a distância, que, assim como Mill (2012), acreditamos que precisam de ser superadas:

[...] as modalidades são tomadas em uma bifurcação equivocada. Antes do caráter complementar a do aspecto espaço-temporal do ensino-aprendizagem, que distingue as duas modalidades, elas são concebidas com hierarquias - em que, geralmente, a EaD é tomada como uma subcategoria (2012, p. 287).

Essa nossa constatação faz-se na medida em que visionamos uma convergência na educação. Para tanto, estamos também de acordo com os argumentos de Gomes (2013), quando esse afirma que

[...] A EaD precisa deixar de ser algo tratado à parte nas instituições escolares, de ser oferecida como uma abordagem, uma modalidade, um ramo de negócio ou apenas como uma oportunidade flexível de acesso à universidade. Porém, os novos paradigmas não podem valer apenas para uma 'modalidade' educacional; essa dicotomia é inadmissível e improdutiva. O meio digital já vem apontando para uma tendência à centralidade da imagem nas comunicações para novas formas de 
relacionamento interpessoal de ampliação dos sentidos do tempo e do espaço, para outras relações de trabalho e para a conectividade ininterrupta. Precisamos, pois, refletir sobre como a educação deve lidar com isso, de modo a fazer parte integrante e agendativa desse mundo, antes que esse mundo seja coisa do passado (2013, p. 22 - grifo do autor).

Outra questão que nos auxiliou a entender a composição da convergência foi: acredita em uma convergência entre educação presencial e a educação distância?

De modo geral, os professores entendem que as modalidades não são concorrentes e, portanto, é possível haver um "casamento" entre elas, ou seja, trabalhar de forma integrada e complementar. Nesta perspectiva, os modelos pedagógicos originais são mantidos, seja presencial ou a distância, mas se aproveita do que "há de melhor" em cada uma delas.

Normalmente, o que acontece na modalidade presencial é o uso de recursos da modalidade a distância, como o ambiente virtual de aprendizagem, sobretudo para a partilha de material, porém, não são desenvolvidas dinâmicas pedagógicas esperadas para a modalidade. Neste caso, torna-se um suporte para tirar dúvidas pontuais, repositório de material ou para outro fim; elas tornam-se complementares, mas ainda estão separadas. 0 contrário também acontece, ou seja, cursos planejados para serem completamente a distância contam com o suporte de Centros Locais de Aprendizagem ou polos (como no caso brasileiro), localizados em diferentes regiões do país, que servem de apoio administrativo e onde acontecem eventuais encontros presenciais.

Deste modo, destacou-se a noção da complementariedade, explicada pelo professor A.M.:

[...] nós deveremos sempre que possível, utilizar estas modalidades porque elas não são concorrentes necessariamente são mais complementares do que concorrenciais. (...) Tendo essas características distintas nós devemos tentar perceber o que quê a modalidade presencial nos oferece e o que tem de melhor e o que a modalidade a distância e que nos pode oferecer, sabendo que a modalidade a distância muitas vezes funciona como complementar ao presencial é aquilo que mais normalmente se utiliza. (...) a complementaridade do ponto de vista da não integração mas da separação e ao mesmo tempo da utilização das duas modalidades. Não sei se estou a fazer entender. Utilizamos as duas modalidades, mas de forma separada. Isso pra mim está a se utilizar essa estratégia e estou a complementar com essa, mas, estou se calhar, a trabalhar de forma separada (Professor AM).

O que nos faz entender que a complementariedade é uma adição; são duas modalidades que se complementam de alguma maneira, elas não concorrem entre si e muito menos se sobrepõem. 
Em nossa ideia inicial, a convergência se comporia pela fusão das modalidades presencial e a distância, com o objetivo central de se alcançar educação de modo integral. Nesse sentido, perderia a adjetivação "modalidade" e as suas distinções compor-se-iam de forma completa em que o processo educativo aconteceria independente da modalidade.

A efetivação da convergência deve levar em consideração dois aspetos: a renovação do modelo pedagógico e a incorporação de estratégias que utilizem tecnologias digitais. De acordo com os entrevistados, a convergência das modalidades é algo deslumbrado para os próximos anos, quando devem ocorrer a superação das noções de modalidades, conforme esclarecem os professores A.M., L.A. e H.C.:

[...] Eu acredito que daqui uns 20 anos ou coisa assim vai deixar de fazer sentido falar em educação presencial e educação a distância. Acho que tudo se vai juntar e que vamos usar as coisas tecnologias e tal, pode-se estar no mesmo lugar, pode-se não se estar; você pode estar, mas eu não estar, tenho essa sensação (LA).

Esta professora, mesmo com alguma incerteza de como este processo vai acontecer, entende que este é um caminho que vem sendo construído e em breve perde-se o sentido de definir as modalidades.

Outro professor corrobora a ideia de que o objetivo final deve ser a aprendizagem, o que importa é que seja alcançado e não o modo como se chegou a este fim, portanto, não fará sentido distinguir as modalidades.

[...] é aquela ideia que alguns autores defendem que é cai o "e" do e-learning para ficar apenas o learning, que é o que interessa que é a aprendizagem. Depois não interessa qual é o ambiente que estou a utilizar, portanto, estou a utilizar todos os recursos que estão ao meu dispor que é aprender (AM).

A convergência é vista tanto como uma tendência, quanto como algo que já acontece. Nós entendemos que este é um processo em construção, por isso as incertezas. Há quase 20 anos já se previa a integração dessas modalidades e na atualidade encontramos experiências que indicam esses caminhos, conforme informa H.C.:

[...] o Professor Rocha Trindade, que era o nosso grande professor fundador da Universidade Aberta de Portugal, ele dizia que daqui há uns 15/20 anos as pessoas começam a deixar de falar de ensino a distância e de ensino presencial porque vamos sempre usar uma mistura dos dois. E a tendência está a ser exatamente esta neste momento. De fato, cada vez mais, o ensino presencial está a usar artefatos, primeiro começou com o hardware, e agora começa a utilizar mesmo estratégias pedagógicas que nós já usamos no ensino a distância há muitos anos (HC). 
Reiteramos que a convergência é vista pelos professores como uma forma de fusão entre as modalidades, envolve a superação de modelos tradicionais tanto da educação presencial, quanto da educação a distância, portanto, não é só uma questão de tecnologia, é uma perspectiva de uma educação integrada.

A partir da análise das categorias, podemos sintetizar as principais ideias no esquema seguinte:

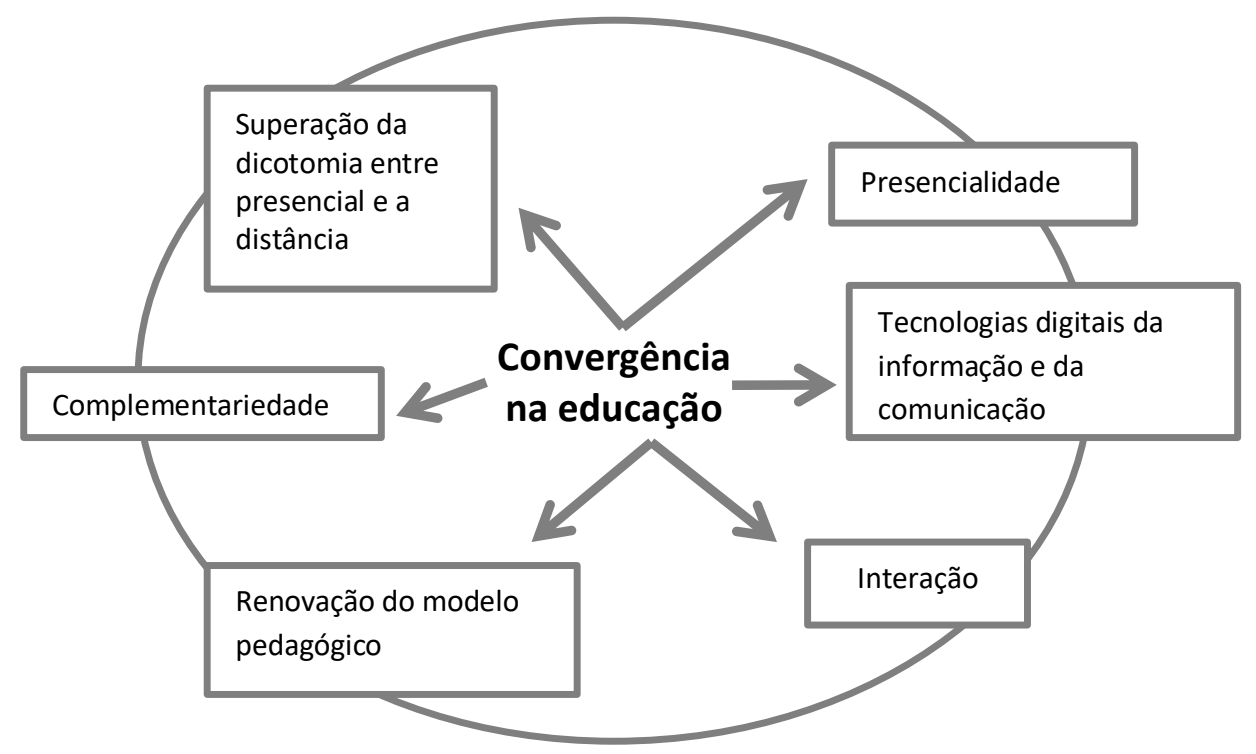

Figura 1: Síntese das análises das entrevistas Fonte: Elaborado pelas autoras

Apesar de a Universidade Aberta ter a sua estrutura fundamentada na oferta virtual, a experiência dos docentes entrevistados permitiu vislumbrar as perspectivas para a convergência na educação presencial e a distância. Eles perceberam que esta é uma dimensão em evolução, que em breve não fará mais sentido a distinção entre educação presencial e a distância. De acordo com os professores, a convergência vislumbra-se como um caminho possível e próximo, em que se falará exclusivamente de educação.

A educação presencial e a distância, que antes eram compreendidas de forma dicotômica, têm-se aproximado tanto por meio de recursos tecnológicos, que permitem uma interação multilateral, quanto por modelos pedagógicos que preveem a colaboração e o diálogo entre os pares. A convergência passa a ser compreendida como uma perspectiva de fusão das modalidades como modo de superar esta dicotomia e pensar a educação como um todo, de forma integral, permitindo uma educação aberta e flexível. Percebemos que as 
entrevistas contribuíram para uma compreensão distinta do que vêm a ser a convergência e as possibilidades para que isso ocorra. Na medida em os professores acreditam que a educação deve ser aberta, inclusiva e os modelos pedagógicos necessitam de renovação, indicam caminhos para a necessidade de uma transformação na educação que não está vinculada somente à inclusão de recursos tecnológicos. É pensar a educação em que as modalidades possam convergir e superar as barreiras físicas e virtuais que há entre elas, pois o objetivo a ser alcançado é a educação como um todo, que cada vez mais deve ser aberta e flexível.

\section{CONSIDERAÇÕES FINAIS}

Tendo por objetivo desse artigo analisar a partir de entrevistas aplicadas as novas percepções sobre a convergência na educação, suas possibilidades e tendências para o ensino superior, os resultados que obtivemos mostram a convergência como um processo em construção, parte da nossa cultura e das relações sociais do tempo presente.

A problemática caracterizada neste texto era se a ocorrência da convergência da educação presencial e da educação a distância poderia tornar-se uma alternativa para o ensino superior e os resultados mostraram-nos que não é só uma alternativa, mas é parte do processo; é cada vez mais difícil distinguir a educação presencial e a educação a distância.

Inicialmente pensávamos que a convergência na educação se daria pela integração da educação presencial e a distância, entretanto, a partir das entrevistas e dos estudos, verificamos que a convergência é uma tendência que envolve aspectos de mudanças tecnológicas, pedagógicas, sociais. Isto porque a convergência se concretiza nas relações sociais estabelecidas entre os sujeitos em rede, em que se verificam a colaboração, a interação, a conectividade, a produção de conteúdos, a partilha, a flexibilidade.

Ao se ter em vista que a convergência é cultural e social e as TDIC são meio de comunicação, sublinhamos, assim, que o essencial na convergência, que também alicerça os elementos da convergência na educação, está no seu caráter social, de fato, porque repetidamente reiteramos: a convergência se faz na interação e na colaboração entre os sujeitos em rede; no seu caráter cultural, pois verificamos e nos modificamos nas formas de 
estar, de nos relacionarmos e de convivermos utilizando as TDIC; e temos as TDIC como meio de comunicação.

Evidenciamos que a convergência ocorre no contexto do informacionalismo, da denominada sociedade em rede, caracterizada por uma cultura da comunicação baseada em tecnologias digitais, em que os tempos são comprimidos; em que se estabelecem novas relações entre o conhecimento, a cultura, o trabalho, as atividades escolares; em que o capital se tornou global, viabilizado pela conectividade da internet e, cada vez mais, dos meios de comunicação sem fio e digitais.

A convergência na educação não é uma tendência ou algo que está por vir. É algo presente nas relações sociais e que, aos poucos, vai sendo incorporado nos modos de fazer a educação. Reconhecemos que a convergência se realiza nas relações sociais e nos usos sociais das TDIC que, estabelecidas em rede, podem estender para espaços físicos, assim como o contrário. Podemos também dizer que acontecem convergências (mesmo no plural), ao se ter em vista que a convergência se entende por uma congregação de fatores para se chegar a um objetivo comum. A convergência na educação acontece numa série de dimensões que pode ser compreendida, por um lado, com a integração da educação presencial e a distância, com o uso mobile learning, com a integração dos materiais didáticos, com o uso de tecnologias (integradas ou não no currículo), com os jogos online, com os modos de estar presente física ou virtualmente, com o modo de entender que os processos educativos são expandidos e não limitados, com a composição de comunidades de aprendizagem.

\section{REFERÊNCIAS}

BARDIN, L. Análise de conteúdo. Lisboa: Edições 70, 1977.

BRASIL. Portaria no 4.059 de 10 de dezembro de 2004. Regulamenta a oferta de carga horária a distância em disciplinas presenciais. Diário Oficial da União. Disponível em: $<$ http://portal.mec.gov.br/sesu/arquivos/pdf/nova/acs_portaria4059.pdf $>$. Acesso em: 09 out. 2012.

CAMPOS, F. A. C. Convergência na educação: processos, tecnologias digitais e relações pedagógicas. 2017. 261p. Tese (Doutorado em Educação) - Faculdade de Educação, Universidade Federal de Minas Gerais, Belo Horizonte, 2017. 
CASTELLS, M. A Galáxia da Internet: reflexões sobre a internet, os negócios e a sociedade. Rio de Janeiro: Zahar, 2003.

CASTELLS, M. O poder da comunicação. Lisboa: Fundação Galouste Gulbenkian, 2013.

CERVANTES, L. M. M. Tendiendo puentes digitales: reflexiones desde la convergencia. Signo y Pensamiento 54, v. XXVIII, p. 56-67, en. - jun. 2009.

DIAS, P. Comunidades de educação e inovação na sociedade digital. Educação, Formação \& Tecnologias (dezembro, 2012), v. 5, n. 2, p. 410, 2013. Disponível em: http://eft.educom.pt Acesso em: maio de 2017.

DIAS, P.; MOREIRA, D.; QUINTAS-MENDES, A. Práticas e Cenários de Inovação em Educação Online. Universidade Aberta. Lisboa, Portugal, 2016. Disponível em:

https://www2.uab.pt/producao/eBooksArea/PCIEO/EaD_e_eLearning_N1.pdf. Acesso em: jan. 2017.

DICIONÁRIO da Língua Portuguesa. Porto: Porto Editora, 2011.

ENYEART, M.; STAMAN, M.; JR VANDES, J. Convergence is real. EDUCAUSE, mar.-abr., 2007, p. 47-58. Tices with other media forms: what potential for learning? A review of the literature. Learning, Media and Technology, v. 33, n. 1, p. 11-20, mar. 2008.

EUROPEAN COMMISSION. Green paper on the convergence of the communications, media and information technology sectors, and the implications for regulation: Towards and Information Society Approach. 1997. Disponível em: <https://ec.europa.eu/digital-singlemarket/en/news/green-paper-convergence-telecommunications-media-and-informationtechnology-sectors-and>. Acesso em: 04 maio 2016.

FREITAS, S.; GRIFFITHS, M. The convergence of gaming practices of other media forms: what potential for learning? A review of the literature. Learning, Media and Technology, v. 33, n. 1, p. 11-20, mar. 2008.

GARRISON, R.; ANDERSON, T.; ARCHER, W. Critical Thinking, Cognitive Presence, and Computer Conferencing in Distance Education. American Journal of Distance Education, $v$. 15, n.1, p.7-23, 2000. Disponível em:

$<$ http://cde.athabascau.ca/coi_site/documents/Garrison_Anderson_Archer_CogPres_Final.p df $>$. Acesso em: 28 set. 2015.

GOMES, L. F. EAD no Brasil: Perspectivas e desafios. Avaliação, Campinas. v. 18, n. 1, p. 1322, mar. 2013.

JENKINS, H. Cultura da convergência. 2. ed. São Paulo: Aleph, 2009. 
LEMOS, A. Cibercultura: tecnologia e vida social na cultura contemporânea. 5. ed. Porto Alegre: Sulina, 2010.

MCLUHAN, M. Visão, som e fúria. Teoria da Cultura de Massa. 7. ed. Rio de Janeiro: Paz e Terra, 2005.

MILL, D. A Universidade Aberta do Brasil. In: LITTO, F.; FORMIGA, M. Educação a Distância: o estado da arte (v. 2). São Paulo: Pearson Education do Brasil, 2012. p. 280-291.

NEGROPONTE, N. A vida digital. São Paulo: Companhia das Letras, 1995.

SANTAELLA, L. Cultura das mídias. São Paulo: Experimento, 1996.

SANTAELLA, L. Por que as comunicações e as artes estão convergindo? São Paulo: Paulus, 2005.

SILVA, M. Educar na cibercultura: desafios à formação de professores para a docência de cursos online. Revista Digital de tecnologias cognitivas, n. 3, p. 36 - 51, jan.- jun, 2010. 